\title{
SCIDOC
}

\author{
International Journal of Dentistry and Oral Science (IJDOS) \\ ISSN: 2377-8075
}

\section{Finite Element Analysis Of Stress Behaviour In A Novel Implant Platform Under Axial and Non - Axial Loading Conditions - An In Vitro Study}

Vinay Sivaswamy ${ }^{1 *}$, Lakshmi Thangavelu², Rathna Subhashini ${ }^{3}$

${ }^{1}$ Associate Professor, Department of Prosthodontics, Saveetha Dental College \& Hospitals, Saveetha University, Chennai, India.

${ }^{2}$ Associate Professor, Department of Pharmacology, Saveetha Dental College \& Hospitals, Saveetha University, Chennai, India.

${ }^{3}$ General Dentist, Chennai, India.

\section{Abstract}

Background \& Rationale: The most common technical complication observed in a dental implant prosthesis post-operatively, is screw loosening and occasionally, screw fracture. The aim of this study is to develop a novel implant-abutment connection which eliminates the use of a prosthetic screw and to evaluate the stress response of this novel connection under axial and non-axial loads simulating the mechanical loads present intraorally.

Materials \& Methods: Three dimensional models of implants with the conventional platform and the new bayonet mount platform were designed. The stress behaviour of the two models were evaluated using finite element analysis under axial and non-axial loading conditions.

Results: Von Mises stresses are higher in the new model in the platform region of the implant fixture. Stress levels were maintained well below the yield limit for the new model under all loading conditions while the conventional design exceeded the yield limit for cortical bone under non-axial loading and in the fastening screw under all loading conditions.

Conclusion: Despite the limitations of the method, it can be observed that the bayonet mount can serve as a suitable alternative implant-abutment connection in commercial implant systems. Further studies need to be performed to evaluate the feasibility of incorporating this platform design in commercial dental implants.

Keywords: Implant-Abutment Connection; Implant Platform; Bayonet Mount; Internal Connection; External Connection; Finite Element Analysis.

\section{Introduction}

An ideal replacement for missing teeth has been the holy grail of dentistry since time immemorial with attempts to replace teeth with ivory, gold, or ornamental décor from the B.C era [1]. The current treatment options for missing teeth include tooth supported fixed dental prostheses, cast partial dentures, conservative resin retained bridges and dental implants $[2,3]$. Dental implants are the most recent inclusion in these options and is considered the most versatile and definitive solution. The other options excluding implants, have been associated with numerous drawbacks over a period of time following therapy. Fixed dental prostheses result in the mutilation of tooth structure in order to provide support for the prostheses from the remaining available teeth. There is also the associated risk of secondary infection and postoperative sensitivity if the abutments are vital. Even when the abutments are endodontically treated, the abutments are weaker than they are naturally due to access cavity preparation and dehydration of dental structures resulting from extirpation of the pulp $[4,5,6]$. Removable prostheses are associated with the stigma of being an inferior substitute since retention cannot be guaranteed in all cases and depends on the support of remaining teeth [7]. Conservative resin retained bridges are in most cases an interim

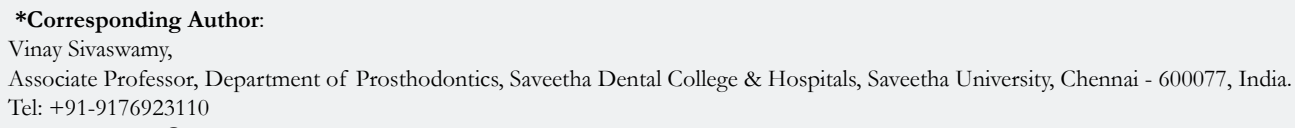

Citation: Vinay Sivaswamy, Lakshmi Thangavelu, Rathna Subhashini. Finite Element Analysis Of Stress Behaviour In A Novel Implant Platform Under Axial and Non - Axial Loading Conditions - An In Vitro Study. Int J Dentistry Oral Sci. 2021;08(06):2709-2715.

Copyright: Vinay Sivaswamy ${ }^{\circ}$ 2021. This is an open-access article distributed under the terms of the Creative Commons Attribution License, which permits unrestricted use, distribution and reproduction in any medium, provided the original author and source are credited. 
solution since it tends to dislodge occasionally, resulting in an unreliable long-term solution [8].

Dental implants serve as an analogue to the root which is lost along with the tooth and aids in providing firm anchorage to the underlying bone. Since bone is maintained by forces distributed from the tooth, bone resorption takes place following the loss of the natural tooth. An implant anchored to bone distributes forces to the surrounding bone similar to the natural tooth and aids in preventing bone resorption [9]. Implants are made of a biocompatible titanium alloy and is an inorganic fixture. Secondary infection which could develop in organic structures is, therefore, non-existent in this inorganic fixture. There have been numerous studies on the success rates of implant prostheses and most studies agree on a cumulative survival rate of over $96 \%$ [10].

Dental Implants are by no means a completely ideal replacement since there are numerous caveats associated with this treatment option [11]. Successful implant therapy relies on healthy bone structure in the patient. The success rate of implant therapy drops considerably in cases of advanced resorption and even in cases of bone augmentation. Though implants are free of secondary dental caries, the peri-implant tissues are overly sensitive to microbial and bio-mechanical stress and could potentially result in Peri-implantitis. Peri-implantitis ranges from a condition which resolves over simple prophylactic procedures to an advanced degree which could result in removal of the implant. The lack of periodontal ligaments deprives the implant of a shock absorbent sensory ligament which alleviates occlusal load during mastication [12]. Implant prostheses have been observed by both patient and clinicians to be more rigid during mastication and requires stringent occlusal calibration compared with prostheses supported by natural teeth. The bite force is increased further on an implant due to the reduced proprioception from tissue around a dental implant. This results in the patient biting harder on the implant prostheses whereas the adjacent teeth are cushioned from occlusal loads by their periodontal ligaments. The most common complications in implants, however, are more technical in nature. The prostheses are secured to the dental implants with the aid of a prosthetic screw. This screw holds the crown/bridge and the implant together and bears the brunt of the stomatognathic load at the interface region. This prosthetic screw and the implant-abutment connection, also known as the implant platform, could be considered the most mechanically weakest areas of a dental implant.

The most common technical complication observed in a dental implant prosthesis post-operatively, is screw loosening and occasionally, screw fracture $[13,14]$. Screw loosening eventually results in prostheses dislodgement and requires the patient to visit the clinician for re-tightening, resulting in a frustrating experience for both the care receiver and care provider simultaneously. Manufacturers recommend applying a preload to the prosthetic screw during prostheses delivery [15]. However, preload simply prolongs the inevitable since consecutive daily mastication results in wear of the screw threads eventually. Screw fracture exponentially complicates treatment further since retrieving the fractured screw requires a specific retrieval kit which is usually manufacturer exclusive and is a highly time-consuming procedure. Removal of the fractured screw may sometimes be feasible only by the use of an air-rotor drill to create purchase points around the fractured screw to safely engage and retrieve it. This also results in destruction of the screw housing making the implant unusable for another pros- theses. The best method to prevent such complications therefore is to develop an implant-abutment connection which does not rely on the use of a prosthetic screw.

Finite element analysis is a biomechanical analysis used to determine stress distribution patterns on objects subjected to loading. It is commonly used in implant dentistry to determine the stress behaviour of varying implant geometry or materials on the surrounding bone. Although this method possesses certain limitations, it is considered a standard testing protocol along with invitro studies for testing novel mechanisms $[16,17,18]$.

The aim of this study is to develop a novel implant-abutment connection which eliminates the use of a prosthetic screw and to evaluate the stress response of this novel connection under axial and non-axial loads simulating the mechanical loads present intraorally.

\section{Materials and Methods}

The methodology followed for this study consists of stress analysis between two types of implant fixtures generated three dimensionally with different implant-abutment connection systems. Implant-abutment connection refers to the mechanism which secures the abutment to the implant fixture. The abutment is secured to the implant fixture using a miniature screw ubiquitously. This traditional design was generated in three dimensions to serve as the comparison standard (Figure 1). Another implant was modelled using a novel bayonet mount mechanism (Figure 1) comprised of two horizontal projections attached to the base of the abutment. The platform region of the implant fixture was modified to eliminate the screw channel instead possessing two slots to which the abutment projections are engaged (Figures $2 \&$ 3). The bayonet mount mechanism relies on frictional retention instead of mechanical tethering as seen in the traditional screw type design. This mounting system eliminates the need for an additional screw to secure the abutment and fixture resulting in zero incidence of screw loosening or screw fracture complications. The frictional retention is supplemented by proximal contact of overlying implant crowns which aid in preventing rotation of the abutment.

The 3D model of the two implants were generated using Solidworks (Dassault Systems). The implants were modelled with a diameter of $5 \mathrm{~mm}$ at the platform region and a length of 11.83 $\mathrm{mm}$ from platform till apex for the fixture. The abutment was generated with a width of $4.5 \mathrm{~mm}$ and a length of $7 \mathrm{~mm}$. A block of bone possessing a width of $9 \mathrm{~mm}$ and height of $20 \mathrm{~mm}$ with no mucosa was also generated to represent the mandible. The bone block consisted of a trabecular centre surrounded by thick cortical bone. The two implant designs along with crowns were screwed into separate bone blocks (Figure 4). The implant fixture and abutment were modelled using titanium alloy with isotropic properties. The bone block was also generated with isotropic properties. The crowns were generated with feldspathic porcelain. The material properties (Table 1) for the implant fixture, abutment, crown, and bone were derived from published literature [19]. The 3D models were then discretised into a mesh with tetrahedral elements using Hypermesh (Altair Engineering) software. There were a total number of 40,964 nodes and 158764 elements for the model with the conventional implant platform. The im- 
plant model with the bayonet mount consisted of 39762 nodes and 158560 elements.

The Implant fixtures were assumed to be completely integrated with bone and were constrained in all three planes. Bonded contact was also established between the abutment and crown interface and cortical and cancellous bone interface. Non bonded contact was established between the fixture and abutment for the bayonet mount model. Insertion torque of $35 \mathrm{Ncm}$ was applied for the implants and a preload of $25 \mathrm{Ncm}$ was applied for the abutment with the conventional platform. Occlusal loads were subjected on the implant and crown in both axial and non-axial directions. Axial loads of $300 \mathrm{~N}$ and $500 \mathrm{~N}$ and a non-axial load of $200 \mathrm{~N}$ directed at 45 degrees to the occlusal plane from the lingual side were applied on both implant models consecutively. A vertical load of $9.8 \mathrm{~N}$ opposite to the path of insertion was also applied to both models. Finite element analysis was performed using Abaqus (Dassault Systems) software. Equivalent von Mises stresses in the implant platforms as well as the surrounding crestal bone was calculated.

\section{Results}

Von Mises stresses indicate the critical point at which a material reaches yield strength beyond which deformation occurs. Von Mises stress values were calculated for both axial and non-axial loading conditions (Table 2). Stress values for the axial pull-out load was also calculated (Table 3). The stress values in the bayonet mount platform are higher in comparison with the conventional platform models (Figure 2).

However, the stress values in both models do not reach the yield limit of either bone or implant components in any of the loading conditions. The yield limit of cortical bone was also exceeded in the conventional platform design when a non-axial load of $500 \mathrm{~N}$ was applied where as the bayonet mount platform had a controlled stress distribution with in the set yield limit. Observation of the abutments in both designs display higher stress concentration in the conventional platform design and reduced stress levels for the new connection. Stress values for the novel platform were

Figure 1. Bayonet mount in Implant fixture.

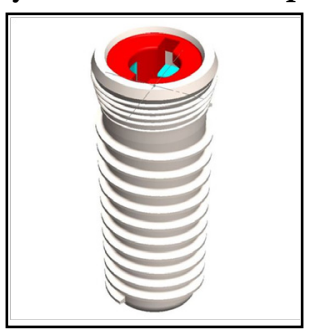

Figure 2. The conventional platform (left) shows stress concentration in the platform and the screw head region whereas the bayonet mount (right) displays stress concentration only in the platform. It should be noted that the stress concentration is higher in the bayonet mount albeit well below the yield limit.

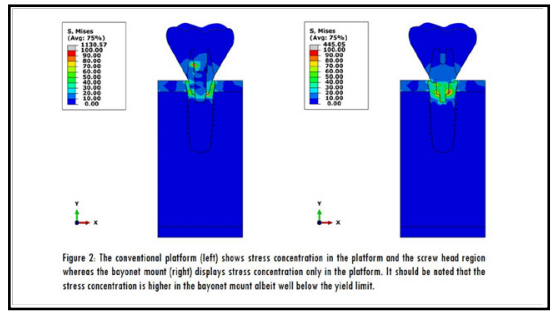

Figure 3. Both the conventional platform (left) and the bayonet mount (right) displays similar stress distribution patternsin bone.

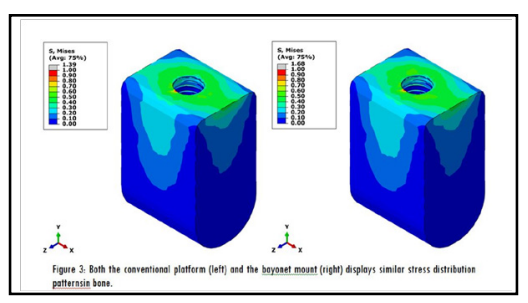

Figure 4. Lower stress levels are observed in the Bayonet abutment (right) than in the conventional abutment (left).

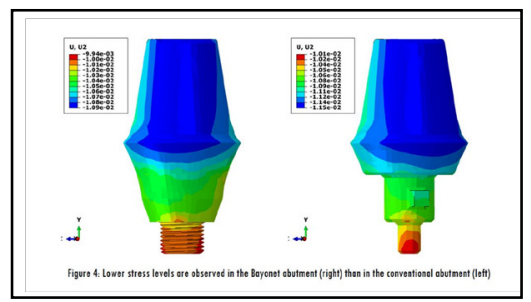


observed to be drastically reduced on the implant crown coupled to the bayonet mount model (Table 2).

The reduced stress values in the cortical bone under non-axial loading indicate a more favourable biomechanical response in surrounding crestal bone with the new platform design. The reduced values for the crown indicate lesser incidence of ceramic chipping or fracture with the bayonet mount platform and the negligible FOS value is indicative of the elimination of screw loosening or fracture. Under axial loading of $300 \mathrm{~N}$ and $500 \mathrm{~N}$ and consecutive non-axial loading of $200 \mathrm{~N}$, the fastening screw in the conventional model displays stress values which exceed the yield limit of the material. The factor of safety (FOS) value is less than 1 for the securing screws in all loading where as the bayonet mount completely bypasses this issue by eliminating the need for a fastening screw (Table 3).

\section{Discussion}

The implant abutment connection plays a crucial role in distribution of stress generated from occlusal load across the long axis of the implant. The point of first contact of stress distribution is along the implant-abutment interface which is usually located at the level of the crestal bone. Both the connection region of the implant fixture and the crestal bone, therefore, imbibe the highest magnitude of the load. Another component which is subjected to these high magnitude load levels is the screw securing the fixture and the abutment. The implant crown is also under heavy stress since the occlusal load is delivered directly across its surface. These aspects of the implants need to be considered as a complex biomechanical entity working in tandem to distribute and dissipate occlusal stress to maintain the anatomic and biologic harmony of the stomatognathic structures [20, 21].

Figure 5. Stress values (MPa) in each component under $300 \mathrm{~N}$ Axial loading.

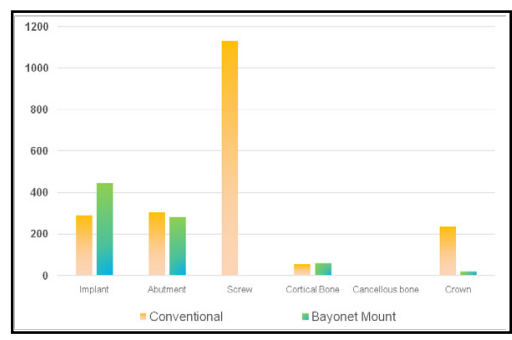

Table 1. Material Properties [19].

\begin{tabular}{|c|c|c|c|c|c|}
\hline Material & Elastic modulus & Poisson's ratio & Tensile strength & Yield strength & Density \\
\hline $\begin{array}{c}\text { Titanium } \\
\text { Alloy }\end{array}$ & $1.048 \times 10^{+011} \mathrm{~N} / \mathrm{m}^{2}$ & 0.31 & $8.2737 \times 10^{+008} \mathrm{~N} / \mathrm{m}^{2}$ & $1.05 \times 10^{+009} \mathrm{~N} / \mathrm{m}^{2}$ & $4428.8 \mathrm{~kg} / \mathrm{m}^{3}$ \\
\hline $\begin{array}{c}\text { Cortical } \\
\text { bone }\end{array}$ & $1.8 \times 10^{+010} \mathrm{~N} / \mathrm{m}^{2}$ & 0.25 & $1.5 \times 10^{+008} \mathrm{~N} / \mathrm{m}^{2}$ & $1.3 \times 10^{+008} \mathrm{~N} / \mathrm{m}^{2}$ & $2000 \mathrm{~kg} / \mathrm{m}^{3}$ \\
\hline $\begin{array}{c}\text { Cancel- } \\
\text { lous bone }\end{array}$ & $1.8 \times 10^{+008} \mathrm{~N} / \mathrm{m}^{2}$ & 0.3 & $2 \times 10^{+007} \mathrm{~N} / \mathrm{m}^{2}$ & $1.8 \times 10^{+007} \mathrm{~N} / \mathrm{m}^{2}$ & $1500 \mathrm{~kg} / \mathrm{m}^{3}$ \\
\hline Ceramic & $2.2059 \times 10^{+011} \mathrm{~N} / \mathrm{m}^{2}$ & 0.22 & - & $5.5149 \times 10^{+008} \mathrm{~N} / \mathrm{m}^{2}$ & $2300 \mathrm{~kg} / \mathrm{m}^{3}$ \\
\hline
\end{tabular}

Table 2. Stress values in the Conventional and Bayonet Mount Platform.

\begin{tabular}{|c|c|c|c|c|c|c|c|}
\hline \multirow{2}{*}{\multicolumn{2}{|c|}{ Loading conditions }} & \multicolumn{6}{|c|}{ Stress (MPa) } \\
\hline & & Cortical bone & Cancellous & Implant & Abutment & Screw & Crown \\
\hline \multicolumn{2}{|c|}{ Yield Stress Limit } & 130 & 18 & 1050 & 1050 & 1050 & 551 \\
\hline \multirow{2}{*}{$\begin{array}{c}\text { Implant Axial Pull Test } \\
9.81 \mathrm{~N}\end{array}$} & Conventional & 10.250 & 0.100 & 253.560 & 302.190 & 75.830 & - \\
\hline & Bayonet & 10.360 & 0.210 & 408.010 & 300.440 & - & - \\
\hline \multirow{2}{*}{$\begin{array}{c}\text { Crown Axial Load Test } \\
500 \mathrm{~N}\end{array}$} & Conventional & 88.860 & 2.320 & 304.590 & 301.990 & 1127.500 & 241.730 \\
\hline & Bayonet & 93.980 & 2.610 & 470.210 & 284.400 & - & 34.370 \\
\hline \multirow{2}{*}{$\begin{array}{c}\text { Crown Axial Load Test } \\
300 \mathrm{~N}\end{array}$} & Conventional & 53.380 & 1.390 & 287.300 & 305.600 & 1130.570 & 236.040 \\
\hline & Bayonet & 59.140 & 1.680 & 445.050 & 282.510 & - & 20.600 \\
\hline \multirow{2}{*}{$\begin{array}{l}\text { Crown Side Load Test } \\
200 \mathrm{~N}\end{array}$} & Conventional & 148.650 & 2.550 & 451.860 & 548.050 & 1144.640 & 253.010 \\
\hline & Bayonet & 120.670 & 2.610 & 716.480 & 837.330 & - & 94.120 \\
\hline
\end{tabular}


Table 3. Factor of Safety (FOS) values in the Conventional and Bayonet Mount Platform.

\begin{tabular}{|c|c|c|c|c|c|c|c|}
\hline \multirow{2}{*}{\multicolumn{2}{|c|}{ Loading conditions }} & \multicolumn{6}{|c|}{ Factor of Safety } \\
\hline & & Cortical bone & Cancellous & Implant & Abutment & Screw & Crown \\
\hline \multicolumn{2}{|c|}{ Yield Stress Limit } & 130 & 18 & 1050 & 1050 & 1050 & 551 \\
\hline \multirow{2}{*}{$\begin{array}{c}\text { Implant Axial } \\
\text { Pull Test 9.81N }\end{array}$} & Conventional & 12.683 & 180.000 & 4.141 & 3.475 & 13.847 & - \\
\hline & Bayonet & 12.548 & 85.714 & 2.573 & 3.495 & - & - \\
\hline \multirow{2}{*}{$\begin{array}{c}\text { Crown } \\
\text { Axial Load Test } \\
500 \mathrm{~N}\end{array}$} & Conventional & 1.463 & 7.759 & 3.447 & 3.477 & 0.931 & 2.279 \\
\hline & Bayonet & 1.383 & 6.897 & 2.233 & 3.692 & - & 16.031 \\
\hline \multirow{2}{*}{$\begin{array}{c}\text { Crown } \\
\text { Axial Load Test } \\
300 \mathrm{~N} \\
\end{array}$} & Conventional & 2.435 & 12.950 & 3.655 & 3.436 & 0.929 & 2.334 \\
\hline & Bayonet & 2.198 & 10.714 & 2.359 & 3.717 & - & 26.748 \\
\hline \multirow{2}{*}{$\begin{array}{c}\text { Crown Side } \\
\text { Load Test } \\
200 \mathrm{~N}\end{array}$} & Conventional & 0.875 & 7.059 & 2.324 & 1.916 & 0.917 & 2.178 \\
\hline & Bayonet & 1.077 & 6.897 & 1.465 & 1.254 & - & 5.854 \\
\hline
\end{tabular}

Technical failures in implant prostheses are considered a norm in their life cycle, with common complicationssuch as screw loosening and more occasional ones such as screw fractures. Screw loosening occurs frequently and is considered a norm in implant restorations with the clinician instructing the patient to report on an annual basis for a review. Manufacturers recommend the application of a preload, a tensile force, to create a clamping force between the fixture and the abutment [15]. The preload is usually applied to approximately 75 percent of the ultimate tensile strength of the prosthetic screw [9]. Preload application results in elongation of the screw which secures more threads in the screw channel. Screw loosening may occur due to premature occlusal contacts or heavy occlusal loads resulting in gradual release of preload torque $[15,16]$. Release of torque can even occur in optimal occlusal conditions albeit in a slower manner. Consecutive loading and unloading during mastication results in micron level contact and separation of the screw and the channel threads. These alternating movements and the micro-roughness of the metal surface results in wear of the contact area on the screw, resulting in reduction of preload and eventual screw loosening [22]. Preload reduction has higher likelihood of incidence in instances of superstructure misfit or non-passivity. Non-passivity results in increased magnitude of axial and bending loads on the framework which contributes to stress concentration in interfacial regions and can even lead to screw fracture [14, 23]. Retrieval of the fractured screw is a cumbersome task for any dental clinician and generally requires the use of an expensive screw retrieval kit for that specific implant system. Screw retrievals may occasionally require the grinding of the inner portion of the implant platform which irreparably damages the connection region. Any amount of damage to the connection region, irrespective of the severity, requires a new implant to be placed which is not an ideal solution for both the patient and the clinician $[24,25]$.

The novel bayonet mount platform evaluated in this study was developed specifically to eliminate the need for a screw to secure fixture and the abutment. Linear elastic analyses on both designs show higher von mises stress levels in the bayonet mount platform model. However, the stress levels observed in the new design do not exceed the yield limit set for all the materials (Bone. Implant, Abutment, Screw and Crown) in all loading conditions.

\section{Implant Fixture}

The Von Mises stress values are of a higher magnitude for the bayonet mount implant primarily in the implant fixture's connection region (Figure 2). However, the elevated values are well with in the yield strength of the titanium alloy which indicates that the platform is capable of delivering high magnitudes stresses across the implant platform with negligible deterioration to the structural integrity of the implant fixture. These values are also similar to the stress levels observed in studies on implant platform conducted separately by Aslam et al [26] and Gurgel-Juarez et al [27]. Their studies aimed to compare the effects of platform switched and platform matched implants for which higher stress values within the yield limit was observed in platform switched implants. The higher values were limited to the implant fixture and not transmitted in the same magnitude to the surrounding bone which indicates that higher loads within the yield strength are favourably distributed by the implant. This indicates that implant fixtures fabricated with the bayonet mount platform will perform in a similar fashion to the conventional internal connection platform design.

\section{Bone}

The stress values are only marginally higher in cortical, cancellous bone in the bayonet mount model which indicate similar stress distribution patterns with that of the conventional platform (Figure 3). Under an axial load of 300 and $500 \mathrm{~N}$, the surrounding cortical and cancellous bone displayed similar levels of von mises stresses in both designs. Similar findings were observed in the axial pull out load as well with minimal difference between the two designs. Under non-axial loading, reduced stress levels were observed in 
crestal cortical bone in the bayonet mount design. Bone is strongest under compressive loading and is weaker to tensile and shear loads. Angled loads impart more tensile and shear stresses on the bone which could lead to bone loss than under axial compression $[9,28]$. Angled loads are likely to occur on implant crowns from the cuspal angulation or from buccal and lingual pressure from the adjacent soft tissue during functions. Premature contacts in implant crowns can also contribute to angled loads on the crestal bone. All these factors could contribute to crestal bone loss which is detrimental to long term survival of the implant $[12,28]$. The reduced stress levels on cortical bone observed in the bayonet mount design indicates favourable stress distribution even under angled loads which could contribute to successful long term clinical performance of the implant. The stress levels observed in the surrounding bone are similar to those observed by Geramizadeh et al $[29,30]$.

\section{Abutment}

Von Mises stresses within abutments of the bayonet mount model were lower in magnitude when compared with those of the conventional platform (Figure 4). This observation is applicable under all loading conditions (Table 2). This could indicate that the newer platform distributes majority of the occlusal loads to the implant platform underneath with reduced stress concentration on the implant superstructures. Clinical longevity of the abutment and crown could be improved by this stress behaviour. Several FEA studies have observed a higher chance of failure with high stress concentration in the abutments. Abutment fracture is a complication which is observed by clinicians occasionally [31, 32]. This complication could be reduced in incidence by the stress behaviour observed in bayonet mount platforms.

\section{Screw}

The fastening screw is generally considered the weakest component of the implant assembly and this observation is corroborated by multiple publications. The application of preload has been the sole method of preventing screw loosening though it is only a temporary measure [13]. Higher magnitude stresses have been observed on the screw in similar FEA analyses by Ji-Hyeon Oh et al [33]. The bayonet mount model, however, does not possess any screw and is thus free of its weakening influence. This statement is corroborated by the factor of safety levels observed for the fastening screw in the conventional platform model (Table 3). Factor of safety refers to ratio of yield stress to working stress. A value of less than 1 indicates that the designed object will yield to deformation or fracture at the applied stress levels. FOS values are lower than 1 for the fastening screw under all loading conditions which indicate that loads of 300 and $500 \mathrm{~N}$ could potentially result in screw fracture with associated complications. The stress values also exceed the yield limit for the screw (conventional platform) in both axial and non-axial loading conditions (Table 2 \& $3)$. The screw-less design could not only contribute to the elimination of technical complications related to the fastening screw but also has the potential to bring down manufacturing costs of the implant components resulting in lower priced implants. Both implant and its components are generally expensive with additional components such as repair kits costing exponentially more. This screw-less design could eliminate these additional expenses and provide a more simplistic fastening solution.

\section{Crown}

Crowns function as foci of stress concentration due to the cuspal slopes. An acute angle of cuspal slopes results in stress concentration at the cusp tips as well as the delivery of angled loads to the implant underneath [34]. Reduction in stress concentration to prevent chipping or fracture is, therefore, a prime objective for crowns atop an implant fixture. This objective is rendered more important with the advent of all ceramic restorations which are brittle and possess lower tolerance to tensile stresses than metal restorations. Lower stress concentration is observed in crowns of the bayonet mount model which could potentially reduce the rate of complications occurring on the restoration during routine masticatory usage (Table $2 \&$ Figure 5). Stress levels observed in the conventional platform are similar to those observed by Bramanti et al [35] in their FEA study on various materials used for implant crowns.

\section{Applications}

The bayonet mount model can be applied as both internal and external connections as required. The design is applicable to both straight and angulated abutments. A horizontal groove or star shaped cavity may be provided atop the abutment to improve handling during insertion or unlocking. The same platform can be applied to all implant components such as cover screw, healing cap, impression copings and abutments.

\section{Limitations Of The Design}

Screw retained restorations are not applicable with the bayonet mount platform. Restoration retrievability could also be cumbersome since a crown removal instrument would be required to remove the crown similar to conventional cement retained restorations. Non engaging abutments with internal connection may not be possible with this design, though external connections incorporating this platform is still feasible.

\section{Limitations Of The Study}

FEA is an effective tool to compute biomechanics for dental implants and is widely used to analyse stress behaviour of newer materials or mechanism on surrounding bone. One caveat associated with the methods is that an accurate representation of the intraoral environment is still not possible due to several variables remaining unpredictable. The nature of bone is still in debate, though most studies lean on bone possessing anisotropic properties. This study assumed the bone to be isotropic in behaviour. Imparting anisotropic properties to bone may provide results which vary to those observed in this study. Another limitation is that bone density was not considered in this study. Bone density varies in different regions and different densities could result in varying elastic behaviour. Bone models rendered from patient derived $\mathrm{CT}$ data to render a realistic representation of osseous anatomy could be used for a more accurate simulation. Static occlusal loads were applied to the implant models which is not an accurate representative of the dynamic loads generated intraorally.

\section{Conclusion}

Despite the limitations of this study, it can be observed that the 
Bayonet mount model is an effective alternative for the conventional implant-abutment connection system in commercial dental implants. The bayonet mount model exhibits higher stress in the implant fixture albeit within the limits of the yield strength of titanium alloy with negligible difference in stress levels on surrounding bone. Stress levels in the abutment and crown are reduced in all loading conditions in the newer model. The screw-less design eliminates technical complications such as screw loosening and fracture and is a more simplistic method for fastening abutments. The design can also potentially reduce manufacturing costs for the implant and associated components. Further studies need to be performed to evaluate the feasibility of incorporating this connection design to commercial implant systems.

\section{References}

[1]. Block MS. Dental Implants: The Last 100 Years. J Oral Maxillofac Surg. 2018 Jan;76(1):11-26. Pubmed PMID: 29079267.

[2]. Guillaume B. Dental implants: A review. Morphol Bull Assoc Anat. 2016 Dec;100(331):189-98.

[3]. Blatz MB, Chiche G, Bahat O, Roblee R, Coachman C, Heymann HO. Evolution of Aesthetic Dentistry. J Dent Res. 2019 Nov;98(12):1294-1304. Pubmed PMID: 31633462.

[4]. Schneider BJ, Freitag-Wolf S, Kern M. Tactile sensitivity of vital and endodontically treated teeth. J Dent. 2014 Nov;42(11):1422-7. Pubmed PMID: 25193521

[5]. Le M, Papia E, Larsson C. The clinical success of tooth- and implant-supported zirconia-based fixed dental prostheses. A systematic review. J Oral Rehabil. 2015 Jun;42(6):467-80. Pubmed PMID: 25580846.

[6]. Ploumaki A, Bilkhair A, Tuna T, Stampf S, Strub JR. Success rates of prosthetic restorations on endodontically treated teeth; a systematic review after 6 years. J Oral Rehabil. 2013 Aug;40(8):618-30. Pubmed PMID: 23663088.

[7]. Oh SH, Kim Y, Park JY, Jung YJ, Kim SK, Park SY. Comparison of fixed implant-supported prostheses, removable implant-supported prostheses, and complete dentures: patient satisfaction and oral health-related quality of life. Clin Oral Implants Res. 2016 Feb;27(2):e31-7. Pubmed PMID: 25346286.

[8]. Thoma DS, Sailer I, Ioannidis A, Zwahlen M, Makarov N, Pjetursson BE. A systematic review of the survival and complication rates of resin-bonded fixed dental prostheses after a mean observation period of at least 5 years. Clin Oral Implants Res. 2017 Nov;28(11):1421-1432. Pubmed PMID: 28191679.

[9]. Misch CE. Dental Implant Prosthetics - E-Book. Elsevier Health Sciences; 2014. 1009 p.

[10]. Pjetursson BE, Valente NA, Strasding M, Zwahlen M, Liu S, Sailer I. A systematic review of the survival and complication rates of zirconia-ceramic and metal-ceramic single crowns. Clin Oral Implants Res. 2018 Oct;29 Suppl 16:199-214. Pubmed PMID: 30328190.

[11]. Pjetursson BE, Heimisdottir K. Dental implants - are they better than natural teeth? Eur J Oral Sci. 2018 Oct;126 Suppl 1:81-87. Pubmed PMID: 30178552.

[12]. Gross MD. Occlusion in implant dentistry. A review of the literature of prosthetic determinants and current concepts. Aust Dent J. 2008 Jun;53 Suppl 1:S60-8. Pubmed PMID: 18498587.

[13]. Kourtis S, Damanaki M, Kaitatzidou S, Kaitatzidou A, Roussou V. Loosening of the fixing screw in single implant crowns: predisposing factors, prevention and treatment options. J Esthet Restor Dent. 2017 Jul 8;29(4):233246. Pubmed PMID: 28556604.

[14]. Abduo J, Judge RB. Implications of implant framework misfit: a systematic review of biomechanical sequelae. Int J Oral Maxillofac Implants. 2014 May-Jun;29(3):608-21. Pubmed PMID: 24818199.

[15]. Jung WK, Lee WS, Kwon HB. Effects of abutment screw preload in two implant connection systems: A 3D finite element study. J Prosthet Dent. 2019 Nov;122(5):474.e1-474.e8. Pubmed PMID: 31590980.

[16]. Geng JP, Tan KB, Liu GR. Application of finite element analysis in implant dentistry: a review of the literature. J Prosthet Dent. 2001 Jun;85(6):585-98. Pubmed PMID: 11404759.

[17]. Manea A, Baciut G, Baciut M, Pop D, Comsa DS, Buiga O, et al. New Dental Implant with 3D Shock Absorbers and Tooth-Like Mobility-Prototype Development, Finite Element Analysis (FEA), and Mechanical Testing. Materials (Basel). 2019 Oct 21;12(20):3444. Pubmed PMID: 31640243.

[18]. Trivedi S. Finite element analysis: A boon to dentistry. J Oral Biol Craniofac Res. 2014 Sep-Dec;4(3):200-3. Pubmed PMID: 25737944.

[19]. Roateşi I. Finite Elements Method in Implant Prosthetics. Perusal of the Finite Element Method. 2016 Dec 14:231.

[20]. Sasada Y, Cochran DL. Implant-Abutment Connections: A Review of Biologic Consequences and Peri-implantitis Implications. Int J Oral Maxillofac Implants. 2017 Nov/Dec;32(6):1296-1307. Pubmed PMID: 29140374.

[21]. Li Z, Gao S, Chen H, Ma R, Wu T, Yu H. Micromotion of implant-abutment interfaces (IAI) after loading: correlation of finite element analysis with in vitro performances. Med Biol Eng Comput. 2019 May;57(5):1133-1144. Pubmed PMID: 30656596.

[22]. Gratton DG, Aquilino SA, Stanford CM. Micromotion and dynamic fatigue properties of the dental implant-abutment interface. J Prosthet Dent. 2001 Jan;85(1):47-52. Pubmed PMID: 11174678.

[23]. Gomes EA, Assunção WG, Barão VA, Delben JA, Rocha EP, de Sousa EA. Passivity versus unilateral angular misfit: evaluation of stress distribution on implant-supported single crowns: three-dimensional finite element analysis. J Craniofac Surg. 2010 Nov;21(6):1683-7. Pubmed PMID: 21119400.

[24]. Ma S, Fenton A. Screw- versus cement-retained implant prostheses: a systematic review of prosthodontic maintenance and complications. Int J Prosthodont. 2015 Mar-Apr;28(2):127-45. Pubmed PMID: 25822297.

[25]. Agustín-Panadero R, Labaig-Rueda C, Castillo-Rodriguez B, Ferreiroa A, Fernanda Solá-Ruíz M. In Vitro Evaluation of Three Methods for the Retrieval of Fractured Screw Fragments from Dental Implants. Int J Oral Maxillofac Implants. 2017 May/June;32(3):e119-e124. Pubmed PMID: 28231345.

[26]. Aslam A, Hassan SH, Aslam HM, Khan DA. Effect of platform switching on peri-implant bone: A 3D finite element analysis. J Prosthet Dent. 2019 Jun;121(6):935-940. Pubmed PMID: 30711297.

[27]. Gurgel-Juarez NC, de Almeida EO, Rocha EP, Freitas AC Jr, Anchieta RB, de Vargas LC, et al. Regular and platform switching: bone stress analysis varying implant type. J Prosthodont. 2012 Apr;21(3):160-6. Pubmed PMID: 22372756.

[28]. Koyano K, Esaki D. Occlusion on oral implants: current clinical guidelines. J Oral Rehabil. 2015 Feb;42(2):153-61. Pubmed PMID: 25284468.

[29]. Geramizadeh M, Katoozian H, Amid R, Kadkhodazadeh M. Static, Dynamic, and Fatigue Finite Element Analysis of Dental Implants with Different Thread Designs. J Long Term Eff Med Implants. 2016;26(4):347-355. Pubmed PMID: 29199621.

[30]. Geramizadeh M, Katoozian H, Amid R, Kadkhodazadeh M. Finite Element Analysis of Dental Implants with and without Microthreads under Static and Dynamic Loading. J Long Term Eff Med Implants. 2017;27(1):25-35. Pubmed PMID: 29604947.

[31]. Coray R, Zeltner M, Özcan M. Fracture strength of implant abutments after fatigue testing: A systematic review and a meta-analysis. J Mech Behav Biomed Mater. 2016 Sep;62:333-346. Pubmed PMID: 27239815.

[32]. Murakami H, Igarashi K, Fuse M, Kitagawa T, Igarashi M, Uchibori S, et al. Risk factors for abutment and implant fracture after loading. J Oral Sci. 2020 Dec 23;63(1):92-97. Pubmed PMID: 33311012.

[33]. Oh JH, Kim YS, Lim JY, Choi BH. Stress Distribution on the Prosthetic Screws in the All-on- 4 Concept: A Three-Dimensional Finite Element Analysis. J Oral Implantol. 2020 Feb 1;46(1):3-12. Pubmed PMID: 31647687.

[34]. Hämmerle CHF, Cordaro L, Alccayhuaman KAA, Botticelli D, Esposito M, Colomina LE, et al. Biomechanical aspects: Summary and consensus statements of group 4. The 5th EAO Consensus Conference 2018. Clin Oral Implants Res. 2018 Oct;29 Suppl 18:326-331. Pubmed PMID: 30306690.

[35]. Bramanti E, Cervino G, Lauritano F, Fiorillo L, D'Amico C, Sambataro S, et al. FEM and Von Mises Analysis on Prosthetic Crowns Structural Elements: Evaluation of Different Applied Materials. ScientificWorldJournal. 2017;2017:1029574. Pubmed PMID: 28474002. 